\title{
Rendimento de grãos de milho e soja em uma sucessão cultural de oito anos sob diferentes sistemas de manejo de solo e de culturas ${ }^{1}$
}

\author{
Corn and soybean grain yield in crop rotations after eight years \\ under different soil tillage and culture systems
}

\author{
Volnei Pauletti ${ }^{2}$ Marcelo Ricardo de Lima ${ }^{3}$ Cristina Barcik ${ }^{4}$ \\ Andreia Bittencourt ${ }^{4}$
}

\section{RESUMO}

Visando estabelecer uma exploração racional $e$ sustentável dos solos, torna-se necessário conhecer os efeitos dos diversos sistemas de manejo do solo e de culturas sobre o potencial produtivo, uma vez que este fator está diretamente relacionado à sua adoção. Desta forma, o presente trabalho teve por objetivo avaliar o rendimento de grãos obtidos nos diferentes sistemas de manejo do solo e de culturas ao longo de uma sucessão cultural de oito anos. O experimento está instalado em Latossolo Vermelho Distrófico típico, em Ponta Grossa (PR), tendo como tratamentos: plantio direto, preparo convencional (uma aração + duas gradagens leves), preparo mínimo (gradagem média + gradagem leve) e plantio direto com escarificação a cada três anos, distribuídos em blocos ao acaso com três repetições. Para a cultura de milho, não foram observadas diferenças significativas de rendimento de grãos quando se compararam os tratamentos e os anos de cultivo. No ano de 1998 o rendimento de grãos de soja do tratamento PD foi inferior aos tratamentos PM e PC. No ano de 2000, esta cultivar foi substituida pela BRS 133, havendo maior rendimento no tratamento $P D$ em relação ao $P C$ e $P M$.

Palavras-chave: preparo de solo, plantio direto, milho, soja

\section{ABSTRACT}

To establish a rational and sustainable use of the soil it is necessary to know the effect of different tillage systems on production considering that this factor is directly related to its choice. The present experiment had the objective to evaluate the grain yield under different soil tillage systems after eight years. The experiment was carried out in an oxisoil, in Ponta Grossa - PR, Brazil. The treatments were: no tillage, conventional tillage (one plow and two light disking), minimum tillage (two light diskings), and no tillage with chisel tillage every three years. The experiment was arranged in randomized blocks with three replications. The tillage systems did not affect the grain yield of corn. In 1998, the grain yield of soybean showed that conventional tillage and minimum tillage were significantly higher than no tillage. However, in 2000, the soybean cultivar was replaced by BRS 133, and grain yield was significantly lower in conventional tillage and minimum tillage than no tillage.

Key words: soil tillage, no-tillage, corn, soybean.

\section{INTRODUÇÃO}

A adoção do sistema plantio direto no Brasil, a partir do início da década de 70, proporcionou novo alento à conservação do solo, a qual se baseava principalmente em práticas mecânicas de controle da erosão, como cultivo em nível e terraceamento (ELTZ, 1997). Os manejos conservacionistas, quando comparados ao preparo convencional, imprimem características químicas, físicas e biológicas distintas ao solo, de maneira a modificar a distribuição e morfologia das raízes, com reflexos no crescimento da

\footnotetext{
${ }^{1}$ Trabalho apresentado na XIII Reunião Brasileira de Manejo e Conservação de Solo e Água, realizada de 6 a 11 de agosto de 2000, em Ilhéus (BA).

${ }^{2}$ Engenheiro Agrônomo, Mestre, Pesquisador da Fundação ABC, Castro (PR)

${ }^{3}$ Engenheiro Agrônomo, Doutorando em Agronomia (PGAPV-UFPR), Professor do Departamento de Solos e Engenharia Agrícola da UFPR, Rua dos Funcionários, 1540, 80035-050, Curitiba, PR. E-mail: mrlima@agrarias.ufpr.br. Autor para correspondência. ${ }^{4}$ Engenheiro Agrônomo, Mestre, Bolsista RHAE/CNPQ.
} 
parte aérea, interagindo conseqüentemente, na produtividade (KLEPKER \& ANGHINONI, 1995).

Experimentos de longa duração são essenciais para avaliar respostas cumulativas para tratamentos de sistemas de manejo, cuja constatação torna-se inviável nos dois ou três primeiros anos. Porém, deve-se considerar ainda que os resultados obtidos nestes experimentos podem ser influenciados pelas condições inerentes à área experimental e à adoção de práticas culturais, além das condições climáticas do ano agrícola, do nível de fertilidade do solo e do estado sanitário da cultura (KLUTHCOUSKI et al., 2000; SOANE \& BALL, 1998). No entanto, as conclusões obtidas, em experimentos de manejo de solo, são restritas às mudanças das características de solo ou à produtividade, sendo necessária uma avaliação das inter-relações dos vários fatores envolvidos nestes sistemas (HILL, 1990). Por estas razões, tem sido variável o comportamento das culturas sob diferentes sistemas de manejo (KLUTHCOUSKI et al., 2000).

Comparando-se sistema plantio direto e preparo convencional, foi observado aumento do rendimento de grãos de milho sob plantio direto, em experimentos de longa duração conduzidos por HERNANI \& SALTON (1997), enquanto outros autores encontraram rendimentos inferiores desta cultura quando conduzidos sob sistema plantio direto (HILL, 1990; SONAE \& BALL, 1998). Em estudo de 20 anos, ISMAIL et al. (1994) encontraram maior rendimento de grãos de milho sob preparo convencional nos primeiros 12 anos, o que se inverteu nos anos seguintes, o que foi atribuído por estes autores à elevação da matéria orgânica no solo sob sistema plantio direto.

Conduzindo experimento de oito anos, KLUTHCOUSKI et al. (2000) verificaram que o rendimento de grãos de soja apresentou estabilidade ao longo do tempo, sendo esta, dentre as principais culturas, a espécie mais adaptada ao sistema plantio direto, independente das possíveis restrições devido à compactação ou à concentração superficial de nutrientes no solo, sob este sistema.

Quando soja é cultivada sob sistema plantio direto, pode apresentar crescimento inicial reduzido, com plantas menos vigorosas, quando comparado ao preparo convencional, no entanto, há um crescimento compensador atingindo produtividade de grãos equiparada em ambos os sistemas (YUSUF et al, 1999). Estes dados são semelhantes aos obtidos por KLUTHCOUSKI et al. (2000).

Este trabalho teve por objetivo avaliar o rendimento de grãos de milho e soja, em diferentes sistemas de manejo de solo e de culturas, ao longo dos anos.

\section{MATERIAL EMÉTODOS}

O experimento está sendo conduzido desde 1989, no Campo Demonstrativo da Fundação ABC, no município de Ponta Grossa - PR, em um Latossolo Vermelho Distrófico típico, em relevo plano (2 a 3\% de declividade), em clima do tipo $\mathrm{Cfb}$ segundo a classificação de Köppen. As características químicas do solo, em cada tratamento, durante o período de estudo, podem ser observadas em LIMA et al. (2000).

Foram instalados quatro tratamentos de sistemas de manejo de solo: PD (plantio direto semeadura sem preparo de solo), PC (preparo convencional - uma aração e duas gradagens leves), PM (preparo mínimo - uma gradagem média e uma gradagem leve), PDE (plantio direto, com escarificação a cada três anos, realizada no inverno). A fertilização foi baseada na análise de solo. O controle de plantas daninhas, pragas e doenças foi realizado conforme as recomendações para cada safra, buscando evitar a influência destes fatores sobre a produtividade das culturas. Na cultura de soja, houve apenas tratamento de sementes com relação ao controle de doenças. Utilizou-se delineamento de blocos ao acaso, com três repetições, sendo que cada parcela media $200 \mathrm{~m}^{2}$. A sucessão cultural adotada (Tabela 1), durante este período, foi a usualmente utilizada na região dos Campos Gerais, sendo que, no presente trabalho, avaliaram-se somente as culturas de verão devido à maior importância econômica. Analisou-se uma série histórica de rendimento de grãos durante o período de 1993 a 2000, representada por três anos de milho e cinco

Tabela 1 - Sucessão cultural adotada no experimento durante o período de 1993 a 2000, em Ponta Grossa (PR)

\begin{tabular}{llccc}
\hline \multirow{2}{*}{ Ano } & \multicolumn{1}{c}{ Inverno } & \multicolumn{3}{c}{ Verão } \\
\cline { 3 - 5 } & & Cultura & Cultivar & Plantas ha $^{-1}$ \\
\hline 1993 & Ervilhaca (comum)* & Milho & P 3072 & 67.865 \\
1994 & Aveia branca (UPF-14) & Soja & BR 16 & 295.256 \\
1995 & Trigo (BR-23) & Soja & BR 16 & 162.552 \\
1996 & Ervilhaca (comum) & Milho & P 3072 & 55.286 \\
1997 & Aveia preta (comum) & Soja & BR 16 & 351.094 \\
1998 & Trigo (BR-23) & Soja & BR 16 & 223.073 \\
1999 & Aveia preta (comum) & Milho & P 30F33 & 53.516 \\
2000 & Aveia branca (Orla 9420) & Soja & BRS & 225.781 \\
& & & 133 & \\
\hline
\end{tabular}

* entre parênteses: cultivares utilizadas 
anos de soja. O rendimento das culturas foi obtido através da massa de grãos colhida em quatro linhas de $5 \mathrm{~m}$, situadas no centro da parcela. Para o tratamento estatístico dos dados, utilizou-se a análise de grupos de experimentos (BANZATTO \& KRONKA, 1992), aplicando-se o teste de comparação de médias de Tukey quando necessário.

\section{RESULTADOS E DISCUSSÃO}

Não foram observadas diferenças significativas em rendimento de grãos de milho nos diferentes sistemas de manejo do solo e anos de cultivo (Tabela 2). Resultados semelhantes foram obtidos, ao se comparar sistema plantio direto e preparo convencional, nas pesquisas conduzidas por MEHDI et al. (1999). Em experimento de nove anos no Rio Grande do Sul, comparando sistema plantio direto, preparo convencional e preparo reduzido, MIELNICZUK (1997) verificou que o rendimento de grãos de milho manteve-se praticamente estável ao longo dos anos, com tendência de maior rendimento no preparo convencional. No entanto, foi observado aumento de rendimento de grãos de milho sob sistema plantio direto, quando comparado ao preparo convencional, nos estudos conduzidos por SMART \& BRADFORD (1999), os quais, porém, trabalharam em ambiente subtropical semiárido.

A ausência de resposta significativa, em rendimento de grãos de milho, é parcialmente explicada pelos estudos de LIMA et al. (2000), que verificaram que os principais atributos de fertilidade química desta mesma área experimental não apresentavam diferenças significativas entre estes tratamentos avaliados.

Apesar de não apresentar diferença significativa no presente experimento, no ano de 1999 ,

Tabela 2 - Rendimento de grãos de milho $\left(\mathrm{Mg} \mathrm{ha}^{-1}\right)$ em uma sucessão cultural no período de 1993 a 2000, em quatro sistemas de manejo de solo, em Ponta Grossa (PR).

\begin{tabular}{lccccc}
\hline Safra/Sistema & PD & PM & PC & PDE & Média (anos) \\
\hline 1993 & 10,5 & 10,5 & 10,2 & 10,4 & $10,4 \mathrm{a}$ \\
1996 & 10,5 & 9,8 & 10,1 & 10,5 & $10,2 \mathrm{a}$ \\
1999 & 10,9 & 10,3 & 9,9 & 10,4 & $10,4 \mathrm{a}$ \\
Média (sistema) & $10,7 \mathrm{~A}^{*}$ & $10,3 \mathrm{~A}$ & $10,1 \mathrm{~A}$ & $10,5 \mathrm{~A}$ & \\
DMS (linha) & \multicolumn{5}{c}{1,5} \\
DMS (coluna) & \multicolumn{5}{c}{6,3} \\
CV (\%) & \multicolumn{5}{c}{}
\end{tabular}

* Médias seguidas da mesma letra maiúscula na linha, e da mesma letra minúscula na coluna não diferem entre si pelo teste de Tukey em $5 \%$ o rendimento de grãos de milho foi $1 \mathrm{Mg} \mathrm{ha}^{-1}$ superior no plantio direto em relação ao preparo convencional, com coeficiente de variação de $6,2 \%$. Embora o teste de Tukey, devido ao rigor, não tenha denotado diferença significativa entre médias, tal acréscimo de rendimento de grãos deve receber atenção do ponto de vista econômico. Deve ser ressaltado que, em condições de lavoura, plantio direto pode apresentar produtividade mais elevada decorrente do controle de erosão (PETRERE et al., 1996).

Para a cultura de soja (Tabela 03), observa-se que, no ano de 1997, o tratamento PC apresentou rendimento de grãos de soja superior ao PDE, bem como no ano de 1998 o tratamento $P C$ foi superior ao tratamento PD. Tal fato pode estar relacionado ao fato de a variedade BR-16 ser classificada como altamente suscetível a oídio, sensível ao crestamento bacteriano, assim como moderadamente resistente ao cancro da haste e à mancha alvo (EMBRAPA, 1999). O plantio direto, por não haver incorporação no solo dos restos de culturas, permite, nos resíduos não decompostos de um ano para outro, a sobrevivência de muitos patógenos que atacam a soja (YORINORI, 1977). O fungo causador de cancro da haste e de oídio, por exemplo, multiplica-se nas primeiras plantas infectadas e, posteriormente, durante o período de entresafra nos restos de culturas (EMBRAPA, 1999). Também, o crestamento bacteriano tem a incidência aumentada no sistema plantio direto (BIANCHINI, 1981). Além disto, deve ser considerada a possível ocorrência de doenças radiculares, que não foram avaliadas no presente ensaio.

No ano de 2000, a cultivar de soja BR16 foi substituída por BRS 133 (Tabela 01), classificada com maiores índices de resistência às doenças (EMBRAPA, 1999), o que parece ter possibilitado maior rendimento de grãos de soja no tratamento PD em relação aos sistemas PC e PM (Tabela 03). Esta hipótese, por enquanto, está respaldada por apenas um ano de cultivo e poderá ser confirmada na continuidade do experimento nos próximos anos. No entanto, na média dos cinco anos, o rendimento de grãos de soja foi equivalente nos quatro sistemas estudados. Ausência de diferenças de rendimento de grãos de soja, em estudos comparando sistemas de manejo de solo e de culturas, também foi relatada por KLUTHCOUSKI etal. (2000) e YUSUF et al. (1999).

Nesta área experimental, não foram observadas diferenças significativas dos principais atributos de fertilidade química do solo (LIMA et al., 2000) entre os sistemas de manejo de solo e de culturas, sugerindo que este fator não tenha apresentado ação pronunciada sobre a variação de rendimento de grãos da cultura de soja, tornando necessário o estudo mais aprofundado de outros fatores que possam ter contribuído para este resultado. 
O rendimento de grãos de soja, no tratamento PD, foi significativamente superior no ano de $2000 \mathrm{em}$ relação a 1998 (Tabela 3). Parece ter havido um efeito favorável da troca de cultivar de soja neste tratamento, pois o rendimento de grãos em 2000 atingiu patamar significativamente semelhante àquele encontrado no início do período estudado (1994 e 1995). No entanto, com relação ao tratamento $\mathrm{PC}$, houve redução significativa do rendimento de grãos em 2000 quando comparado a 1994, 1997 e 1998. No tratamento PM, o rendimento de grãos de soja obtido em 2000 foi inferior ao de 1994.

Tabela 3 - Rendimento de grãos de soja $\left(\mathrm{Mg} \mathrm{ha}^{-1}\right)$ em uma sucessão cultural no período de 1993 a 2000, em quatro sistemas de manejo de solo, em Ponta Grossa (PR).

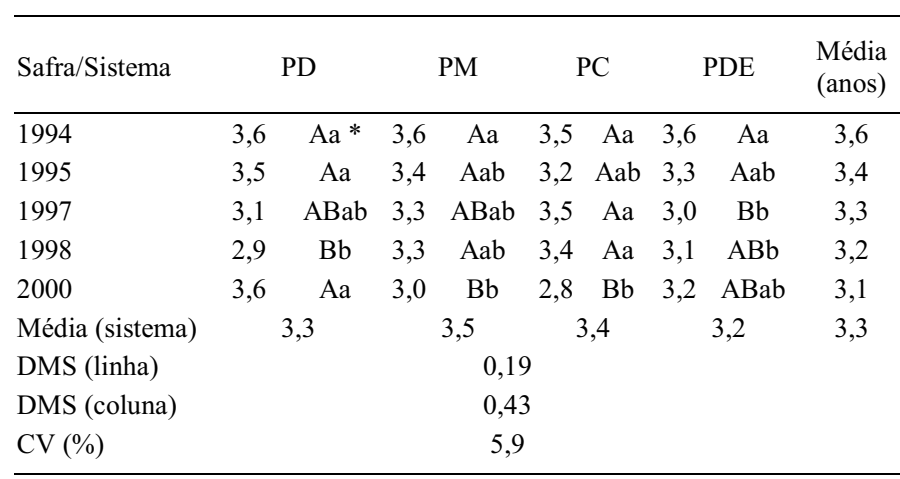

* Médias seguidas da mesma letra maiúscula na linha, e da mesma letra minúscula na coluna não diferem entre si pelo teste de Tukey em 5\%

\section{CONCLUSÕES}

O rendimento de grãos de milho não foi afetado pelos sistemas de manejo de solo e de culturas ao longo dos anos. No ano de 1998, o rendimento de grãos de soja do tratamento PD foi inferior aos tratamentos PM e PC, fato atribuído a problemas fitossanitários da cultivar BR 16. No ano de 2000, esta cultivar foi substituída pela BRS 133, havendo maior rendimento no tratamento $\mathrm{PD}$ em relação aos tratamentos PC e PM.

\section{AGRADECIMENTO}

Ao Conselho Nacional de Desenvolvimento Científico e Tecnológico (CNPq) pelo apoio através da concessão de bolsas do Programa RHAE aos pesquisadores deste projeto.

\section{REFERÊNCIAS BIBLIOGRÁFICAS}

BANZATTO, D.A.; KRONKA, S. do N. Análise de grupos de experimentos. In: Experimentação agrícola. 2.ed. Jaboticabal : FUNEP, 1992. Cap. 8, p.213-236.
BIANCHINI, A. Ocorrência e controle de doenças: cultura da soja. In: IAPAR. Plantio direto no Estado do Paraná. Londrina : IAPAR, 1981. p.178-182. (Circular técnica, 23).

ELTZ, F.L.F. Ensino de plantio direto. In: PEIXOTO, R.T. dos G.; AHRENS, D.C.; SAMAHA, M.J. (Eds). Plantio direto: o caminho para uma agricultura sustentável. Ponta Grossa : IAPAR-PRP/PG, 1997. p.39-42.

EMBRAPA. Centro Nacional de Pesquisa de Soja. Doenças e medidas de controle. In: Recomendações técnicas para a cultura da soja no Paraná - 1999/2000. Londrina, 1999. Cap.11, p.176-210. (Documentos, 131).

HERNANI, L.C.; SALTON, J.C. Milho: informações técnicas. In: EMBRAPA. Centro de Pesquisa Agropecuária do Oeste. Manejo e conservação de solos. Dourados : EMBRAPA/CPAO, 1997. p.39-67. (Circular técnica, $05)$.

HILL, R.L. Long term conventional and no-tillage effects on selected soil physical properties. Soil Science Society American Journal, Madison, v.54, p.161166,1990

ISMAIL, I.; BLEVINS, R.L.; FRYE, W.W. Long-term no-tillage effects on soil properties and continuous corn yields. Soil Science American Journal, Madison, v.58, n.1, p.193-198, 1994.

KLEPKER, D.; ANGHINONI, I. Características físicas e químicas do solo afetadas por métodos de preparo e modos de aplicação. Revista Brasileira de Ciência do Solo, Campinas, v.19, n.3, p.395-401, 1995.

KLUTHCOUSKI, J. et al. Manejo do solo e o rendimento de soja, milho, feijão e arroz em plantio direto. Scientia Agrícola, Piracicaba, v.57, n.1, p.97-104, 2000.

LIMA, M.R. et al. Características químicas de um latossolo vermelho ao longo de um período de seis anos sob diferentes sistemas de preparo de solo e semeadura. In: REUNIÃO BRASILEIRA DE FERTILIDADE DO SOLO E NUTRIÇÃO DE PLANTAS, 24., 2000, Santa Maria. Resumos... Santa Maria : SBCS, SBM, 2000. p.197.

MEHDI, B.B.; MADRAMOOTOO, C.A.; MEHUYS, G.R. Yield and nitrogen content of corn under different tillage practices. Agronomy Journal, Madison, v.91, n.4, p.631-636, 1999.

MIELNICZUK, J.A. Sustentabilidade agrícola e o plantio direto. In: PEIXOTO, R.T. dos G.; AHRENS, D.C.; SAMAHA, M.J. (Eds). Plantio direto: o caminho para uma agricultura sustentável. Ponta Grossa : IAPAR-PRP/PG, 1997. p.9-12.

PETRERE, C.; SALET, R.L.; ANGHINONI, I. Produtividade de culturas nos sistemas plantio direto e convencional no sul do Brasil. In: REUNIÃO SUL-BRASILEIRA DE CIÊNCIA DO SOLO, 1., 1996, Lages. Resumos Expandidos... Lages : SBCS-NRS, 1996. p.76-78.

SMART, J.R.; BRADFORD, J.M. Conservation tillage corn production for a semiarid, subtropical environment. Agronomy Journal, Madison, v.91, n.1, p.116-121, 1999. 
SOANE, B.D.; BALL, B.C. Review of management and conduct of long-term tillage studies with special reference to a 25 years experiment on barley in Scotland. Soil \& Tillage Research, Amsterdam, v.45, n.1, p.17-37, 1998

YORINORI, J.T. Doenças da soja. In: FUNDAÇÃO CARGILL.
A soja no Brasil central. Campinas : Fundação Cargill, 1977. p.159-215.

YUSUF, R.I.; SIEMENS, J.C.; BULLOCK, D.G. Growth analysis of soybean under no-tillage and conventional tillage systems. Agronomy Journal, Madison, v.91, n.6, p.928-933, 1999.

Ciência Rural, v. 33, n. 3, mai-jun, 2003. 